\title{
Analysis of YAG Laser-Induced Damage in Intraocular Lenses: Characterization of Optical and Surface Properties of YAG Shots
}

\author{
Andreas F. Borkenstein Eva-Maria Borkenstein \\ Borkenstein \& Borkenstein, Privatklinik der Kreuzschwestern Graz, Graz, Austria
}

\section{Keywords}

YAG shots - Pitting of intraocular lenses - Hydrophilic .

Hydrophobic · Defects in intraocular lens

\begin{abstract}
Purpose: To assess differences in neodymium:yttrium aluminum garnet (Nd:YAG)-induced defects in hydrophilic and hydrophobic intraocular lenses (IOLs) and describe optical and surface properties of YAG shots/pitting. Describing and measuring the iatrogenic produced defects should achieve higher awareness on this topic and change the mindset of such a trivial procedure to be proceeded with more caution and calmness in the future. Materials: Twelve IOLs from different manufacturers made of hydrophilic and hydrophobic materials were evaluated before and after treatment with the Nd:YAG laser. Microscopy and environmental scanning electron microscopic (ESEM) images were used to visually analyze the defects. Additionally, wavefront measurements were taken for power mapping and Raman spectroscopy was performed. Vertical and horizontal dimensions of the defects were analyzed and compared, and Raman line scans assessed the changes in the chemical structure in the defect area of the IOL. Results: Microscopically, pitting of the surface could be observed in both lens types. Defects in hydrophobic lenses appeared bigger and were visible with less
\end{abstract}

magnification than in hydrophilic lenses. Similar results were obtained with ESEM images where the defects in hydrophobic IOLs seemed to be frayed while defects in hydrophilic IOLs were of circular shape. Raman spectroscopy revealed deeper defects in hydrophobic lenses. Vertical dimensions of the defects were statistically significant $(p=0.036)$ and greater in hydrophobic materials while horizontal dimensions did not reach significance $(p=0.056)$. The area of chemical changes was greater than the visible defect area and smaller in hydrophilic than that in hydrophobic materials. Conclusion: Nd:YAG seems to have greater impact on hydrophobic IOL materials as that damage was greater and more frayed than that in hydrophilic materials. Moreover, there seems to be larger, distinctive damage area in IOLs (with chemical changes in the material) than that is visually recognizable. Therefore, a very cautious approach is recommended when performing capsulotomy, as defects in the surface structure can occur. This might come along with problems in quality of vision in monofocal and primarily premium IOLs (multifocal, enhanced depth of focus, and toric IOLs), dependent on the size, dimension, and position in the IOL. YAG capsulotomy should not be considered trivial but should be carried out with precision and without time pressure, just like surgery itself.

(c) 2020 The Author(s).

Published by S. Karger AG, Basel karger@karger.com www.karger.com/ore

Karger $\stackrel{\text { ' }}{5}$

GOPEN ACCESS
(C) 2020 The Author(s)

Published by S. Karger AG, Basel

This is an Open Access article licensed under the Creative Commons Attribution-NonCommercial-4.0 International License (CC BY-NC) (http://www.karger.com/Services/OpenAccessLicense), applicable to the online version of the article only. Usage and distribution for commercial purposes requires written permission.
Andreas F. Borkenstein

Private Practice, Privatklinik der Kreuzschwestern Graz Kreuzgasse 35

AT -8010 Graz (Austria)

crustalith@gmx.at 


\section{Introduction}

Hydrophilic and hydrophobic acrylic intraocular lens (IOL) materials are heavily discussed, and opinions vary greatly. Some reports present evidence on equally good visual and refractive outcomes [1] between the 2 materials, while others focus on the enhanced risk for glistenings in hydrophobic materials [2] and higher probability of posterior capsular opacification (PCO) in hydrophilic materials [3]. PCO, however, is not only related to material but also to IOL design [4]. A sharp optic edge [5] for instance can act as a barrier to the migration of lens epithelial cells and result in decreased PCO. A larger optic diameter might also reduce formation of PCO [6]. Since PCO can reduce visual acuity (VA), decrease contrast sensitivity, and increase retinal straylight, this condition must be treated. Neodymium: yttrium aluminum garnet (Nd:YAG) laser capsulotomy is a well-accepted, safe, and effective measure in the treatment of PCO [7]. It improves VA and may also have positive effects on glare and contrast sensitivity in some patients. However, there are reports on complications [8] such as corneal injuries, pupil blockage, iritis, intraocular pressure rise [9], vitreous prolapse, retinal damage, and IOL dislocation [10] or impairment. The 2 materials, hydrophilic and hydrophobic, seem to be affected differently by Nd:YAG treatment in terms of wavefront aberrations [11]. Lens material did not influence laser energy levels though higher laser energy levels were found to cause greater damage and should therefore be kept low [12]. Different wavefront outcomes in those 2 material types were found after Nd:YAG treatment, to our knowledge the severity of the damages after the treatment were not examined in terms of differences between the materials. With this experimental in vitro study, we aimed at getting more insight into the different amounts of damage that Nd:YAG causes in hydrophilic and hydrophobic lens materials.

\section{Material and Methods}

In this experimental in vitro study, the YAG laser was performed at our facility and measurements were also taken at the laboratories of the University of Technology Graz, Austria (Raman spectroscopy, light microscopy, and environmental scanning electron microscope [ESEM]), at HumanOptics AG, Erlangen, Germany (analysis of optical properties) and at Trioptics, Wedel, Germany (Wavemaster, measurement of refractive power, aberrations, and modulation transfer function [MTF]).

IOLS

A total of 12 different monofocal IOLs from 9 manufacturers were evaluated. Table 1 shows the characteristics of the lenses with their material as a group indicator (hydrophilic: $n=5$ and hydro- phobic: $n=7$ ). Of the 5 hydrophilic IOLs, one was yellow and the others were made of clear material. All 5 lenses had a refractive index of 1.46 and a water content of $26.0 \%$. Of the 7 hydrophobic IOLs, 2 were yellow and 1 had an additional heparin coating. Refractive index varied between 1.47 and 1.55, the water content was $<1.0 \%$ except for one lens with a water content of $4.0 \%$. All lenses were manufactured with a $360^{\circ}$ sharp edge and the spherical power was 21.5 diopters (D).

\section{Nd:YAG Procedure}

We used a Q-switched Nd:YAG laser system (Visulas YAG III, Carl Zeiss, Germany) with wavelength of 1,064 nm and pulse length of $<4$ ns. Lenses were placed within a transparent glass cuvette, which was fixed to the head- and chin rest. The aiming beam was focused directly on the IOL optic center. IOL material was found to not influence laser energy levels [12]; therefore, exactly the same level was used for each lens. Five shots in each lens with an energy level of 1.8 millijoule $(\mathrm{mJ})$ were performed and summated laser energy, hence, was $5 \times 1.8 \mathrm{~mJ}$ per lens.

\section{Light Microscopy}

High-resolution images were taken with Keyence VHX-2000D (Keyence $\mathrm{GmbH}$, Neu-Isenburg, Germany) to assess the visible damages with different magnification factors. All IOLs (hydrophilic and hydrophobic) were prepared by rinsing them in saline solution. The lenses were placed within a saline droplet on glass slides and care was taken that the lenses, especially hydrophilic ones, did not dehydrate. Images for the 2 material groups were compared by subjective picture analysis.

\section{ESEM}

After the Nd:YAG treatment, images with the Fei Quanta 600 FEG (Thermo Fisher Scientific, Waltham, USA) ESEM with an additional Peltier-cooled specimen stage were taken to further assess the morphology and differences of the defects within the 2 materials. A standard SEM (high vacuum) analysis would lead to dehydration of the lenses and therefore radical changes of the surface properties due to the water content of the IOLs. Therefore, measurements were taken in a cooled state (approximately $4^{\circ} \mathrm{C}$ ) in a water vapor atmosphere (to prevent sample outgassing). Images of the hydrophilic IOLs were compared to those of the hydrophobic lenses and defects were subjectively evaluated.

\section{Raman Spectroscopy}

Raman spectroscopy was applied to more accurately examine the defects and the chemical changes due to Nd:YAG treatment. All Raman measurements were performed with the LabRam 800 HR spectrometer (Horiba Jobin Yvon GmbH, Bensheim, Germany), equipped with a $1024 \times 256$ CCD camera (Peltier cooled) adapted to an Olympus BX41 microscope. All measurements were carried out with a laser wavelength of $532 \mathrm{~nm}(5 \mathrm{~mW})$, an integration time of $1 \mathrm{~s}$ per spectrum and an Olympus x10 MPlanN (NA = $0.25)$ lens. Each spectral image had a total size of $7,200 \times 6,800 \mu \mathrm{m}$ with a step width of $50 \mu \mathrm{m}$ and uses the DuoScanTM Imaging system to map the laser focus to the pixel size. Raman spectra were acquired in the region of $250-3,250 \mathrm{~cm}^{-1}$. The photoluminescence of the defect and surrounding intact area as a reference were used to assess the influence of the defects on optical performance of the lenses. The damage lengths (visible and spectroscopic) were detected horizontally and vertically (Fig. 1). 
Table 1. Details of the different monofocal lens types

\begin{tabular}{|c|c|c|c|c|c|c|}
\hline Manufacturer & IOL name & $\begin{array}{l}\text { Material } \\
\text { type }\end{array}$ & $\begin{array}{l}\text { Water } \\
\text { content, \% }\end{array}$ & $\begin{array}{l}\text { Refractive } \\
\text { index }\end{array}$ & $\begin{array}{l}\text { Optic/IOL } \\
\text { diameter, mm }\end{array}$ & $\begin{array}{l}\text { IOL } \\
\text { power, D }\end{array}$ \\
\hline Domilens & $125 \mathrm{DS}$ & Hydrophilic & 26.0 & 1.46 & $6.0 / 12.5$ & 21.5 \\
\hline HumanOptics & Aspira-aA & Hydrophilic & 26.0 & 1.46 & $6.0 / 12.5$ & 21.5 \\
\hline HumanOptics & Aspira-aXA & Hydrophilic & 26.0 & 1.46 & $7.0 / 11.0$ & 21.5 \\
\hline HumanOptics & Aspira-aAY & Hydrophilic/yellow & 26.0 & 1.46 & $6.0 / 12.5$ & 21.5 \\
\hline Rayner & ADV 970 & Hydrophilic & 26.0 & 1.46 & $5.8 / 12.0$ & 21.5 \\
\hline Alcon & Acrysof SA60AT & Hydrophobic & $<0.3$ & 1.55 & $6.0 / 13.0$ & 21.5 \\
\hline Bausch + Lomb & EnVista MX60 & Hydrophobic & 4.0 & 1.54 & $6.0 / 12.5$ & 21.5 \\
\hline Cristalens & ARTIS PL E & Hydrophobic & $<1.0$ & 1.54 & $6.0 / 10.79$ & 21.5 \\
\hline Hoya & iSert 255 & Hydrophobic/yellow & $<0.5$ & 1.52 & $6.0 / 12.5$ & 21.5 \\
\hline Hoya & Vivinex iSert XY1 & Hydrophobic/yellow & $<0.5$ & 1.52 & $6.0 / 13.0$ & 21.5 \\
\hline Johnson \& Johnson & Tecnis PCB00 & Hydrophobic & $<1.0$ & 1.47 & $6.0 / 13.0$ & 21.5 \\
\hline Zeiss & CT Lucia 611P & Hydrophobic + heparin & 0.3 & 1.49 & $6.0 / 13.0$ & 21.5 \\
\hline
\end{tabular}

IOL, intraocular lens.

Fig. 1. Example of a light microscopic image of the Raman measurements showing the visible horizontal and vertical length of the defect.

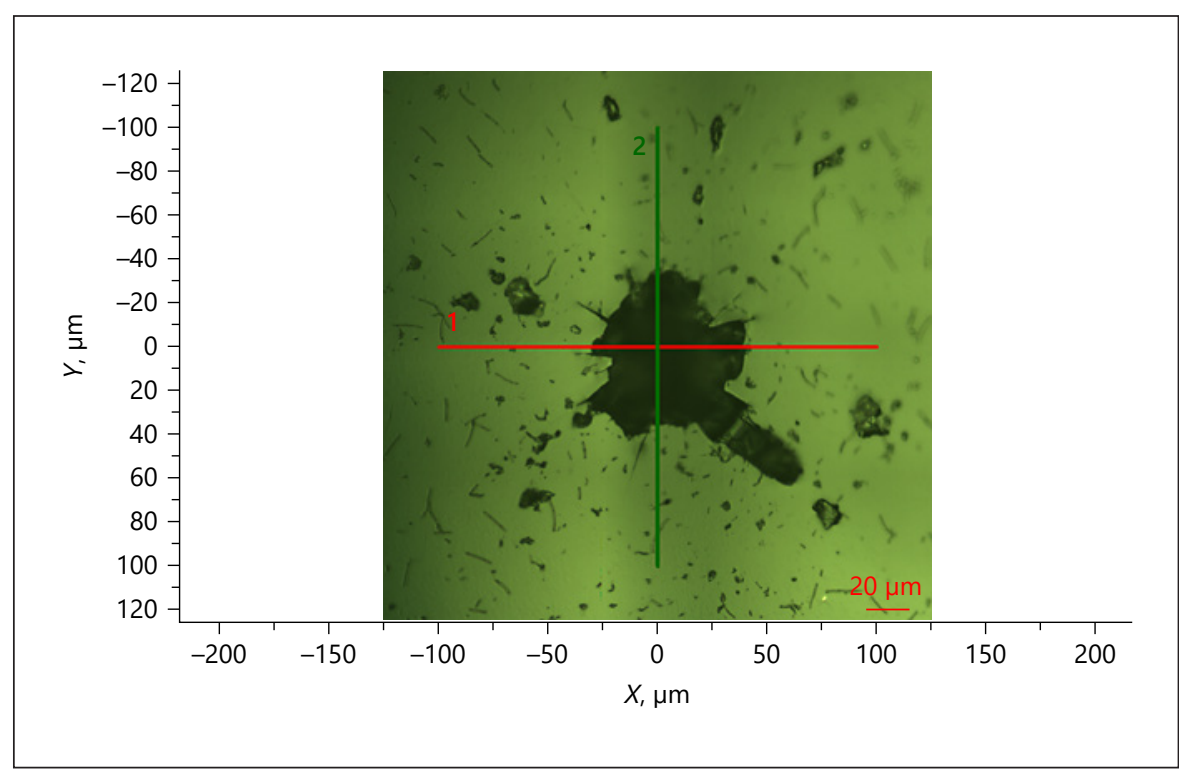

\section{Optical Properties}

Before and after the YAG laser procedure, measurements with NIMO TR0815 (LAMBDA-X, Nivelles, Belgium) were performed. The device combines the Schlieren principle with a phase shifting method. It measures the optical properties, such as MTF and Strehl ratio with a wavelength of $546 \mathrm{~nm}$. The MTF is the amplitude of the image contrast divided by the amplitude of the object contrast and is a function of spatial frequency. It, therefore, describes how perfectly an optical system transfers the details of an object into an image. The number of line pairs per millimeter $(\mathrm{lp} / \mathrm{mm})$ defines the spatial frequency which decreases the contrast with increasing number. The Strehl ratio is a measure for quality of vision as it enables the comparison of the maximum aberrated image intensity from a point source to the maximum achievable intensity using an ideal, diffraction-limited optical system.

YAG Shots in IOLs Overrated or Serious

Complications after Capsulotomy?
All lenses were positioned in a quartz cuvette filled with buffered salt solution ( $0.9 \%$ sodium chloride). Measurements were performed at 2.0,3.0, and $4.5 \mathrm{~mm}$ optical apertures and at 25, 50, and $100 \mathrm{lp} / \mathrm{mm}$. The Strehl ratio was measured with the same apertures. Based on wavefront analysis, WaveMaster ${ }^{\circledR}$ IOL 2 measures key parameters of refractive IOLs using the well-established Shack-Hartmann sensorWaveSensor ${ }^{\circledR}$. Measurement parameters like the refractive power, aberrations, and MTF are calculated by analyzing the wavefront which is obtained in a measurement process.

\section{Statistical Analysis}

Statistical analysis was performed using $\mathrm{R}$ software [13] and figures were produced using the package ggplot2 [14]. Variables were described with descriptive statistics ( $n$, mean, standard de- 

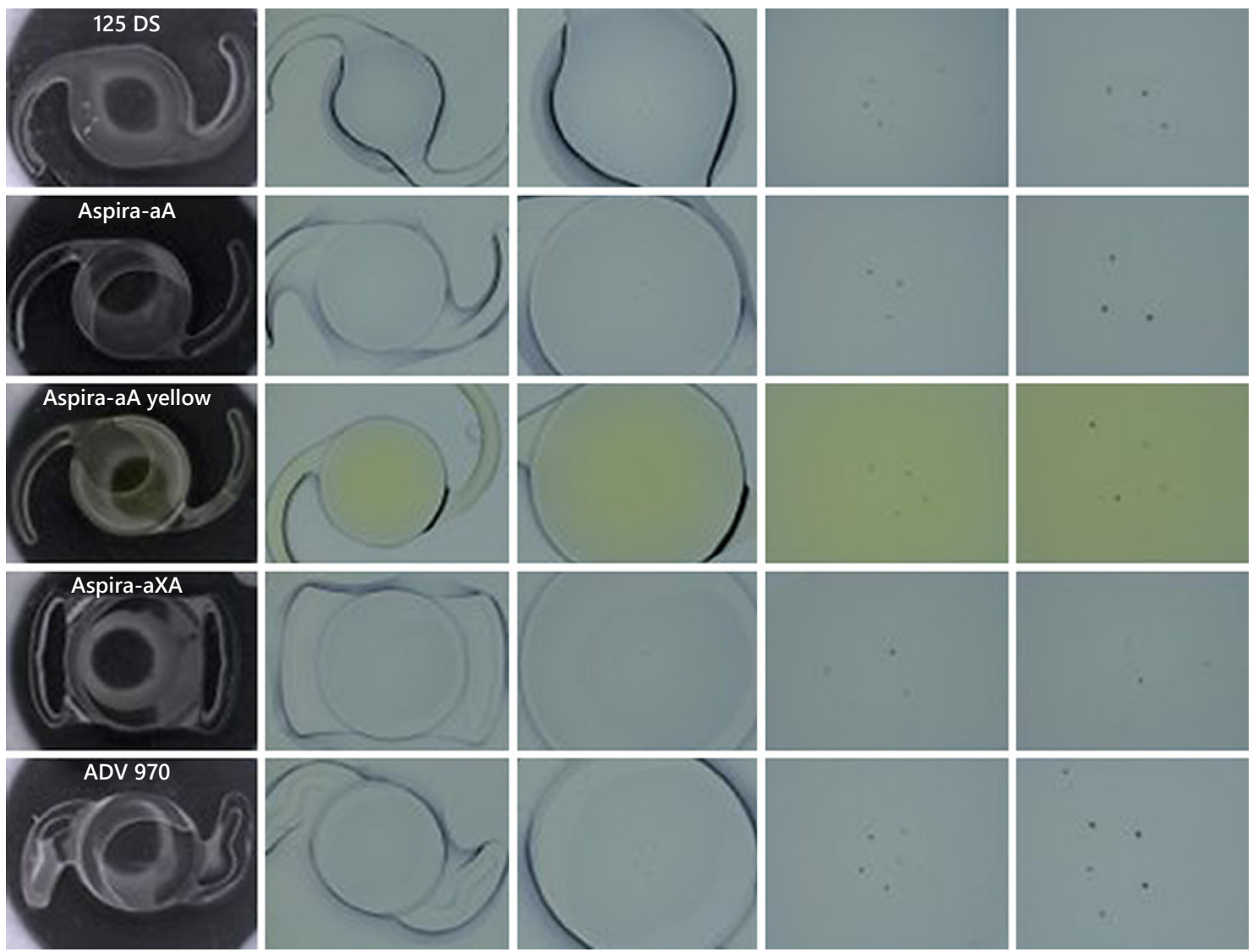

Fig. 2. Microscopy images of all 5 hydrophilic IOLs included in this study before (gray images) and after (blue images) Nd:YAG laser treatment. IOLs, intraocular lenses; Nd:YAG, neodymium:yttrium aluminum garnet.

viation, median, and range). Data were tested for normality with the Shapiro-Wilk test. Comparison between the 2 material groups was performed with the $t$ test for normally distributed variables and Wilcoxon test for nonparametric data. A $p$ value $<0.05$ was considered statistically significant.

\section{Results}

\section{Microscopy}

Figures 2 and 3 show photomicrographs of the hydrophilic and hydrophobic IOLs after laser treatment. Due to the nonsterile conditions in the laboratory setting, small fibers and dust-like deposits may be visible. After the treatment, pits created by the laser can be seen on both types of materials. Within the hydrophobic lenses, that damage appears to be bigger and more intense than that in hydrophilic lenses. In the hydrophobic lenses, those pits look similar to branched out glass breakage and can be seen even with less magnification while in hydrophilic they are not as visible, hence smaller. This smaller damage appears like bullet holes with a smoother rim. An additional observation was that the shots directly next to already existing defects produced larger crater. This suggests that the change in the material around the defect might lead to that.

\section{ESEM}

The ESEM images (Fig. 4) also show deeper and bigger damages in hydrophobic (right column) materials than in hydrophilic (left column). Damage in hydrophilic lenses seems to be more circular while that in hydrophobics is more frayed.

\section{Raman Spectroscopy}

For the measurement with Raman spectroscopy there were no statistically significant differences between both groups in terms of horizontal visible damage length $(p=$ 

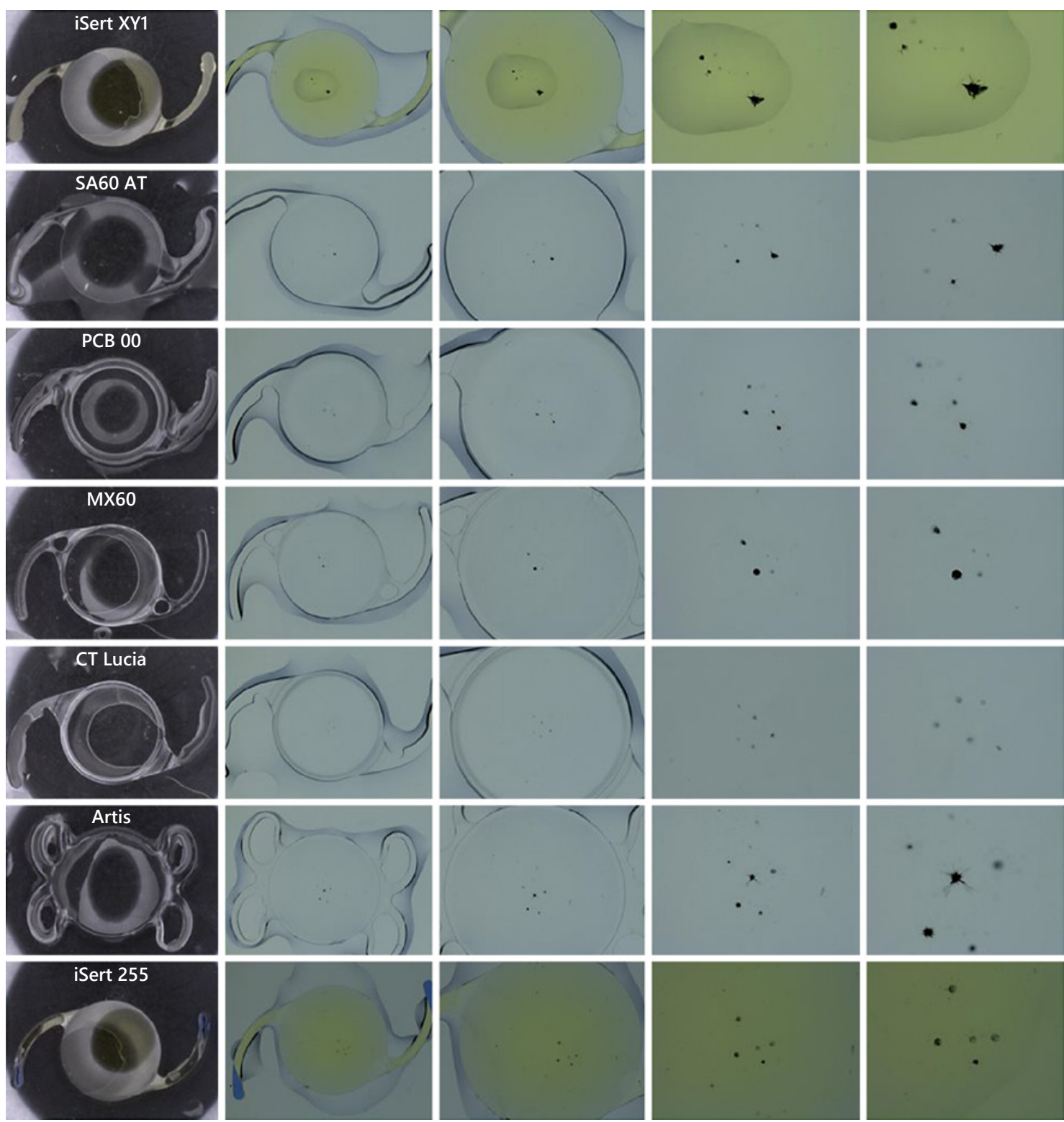

Fig. 3. Microscopy images of all 7 hydrophobic IOLs included in this study before (gray images) and after (blue images) Nd:YAG laser treatment. IOLs, intraocular lenses; Nd:YAG, neodymium:yttrium aluminum garnet.

0.056), but for vertical visible damage length $(p=0.036)$ hydrophilic lenses showed statistically significant smaller damage (Fig. 5). A subjective comparison between hydrophilic and hydrophobic images supports these findings (Fig. 6). Defects were found to be different in depth, with deeper pits in hydrophobic lenses (Fig. 7, 8).

Raman line scans (example Fig. 9) showed the area of defect in terms of chemical changes. Those areas were found to be bigger than the visible defect area and again greater in hydrophobic lenses. This is shown in the signal of photoluminescence (Fig. 10a, b bright red line $=$ horizontal measurement, green line $=$ vertical measurement) where chemical changes are greater than the visible damage (Fig. 10b, dark red line $=$ horizontal and yellow line $=$ vertical).

\section{Optical Properties}

Values from before to after the treatment did not differ significantly within each group. No statistically significant differences were found between the groups in 

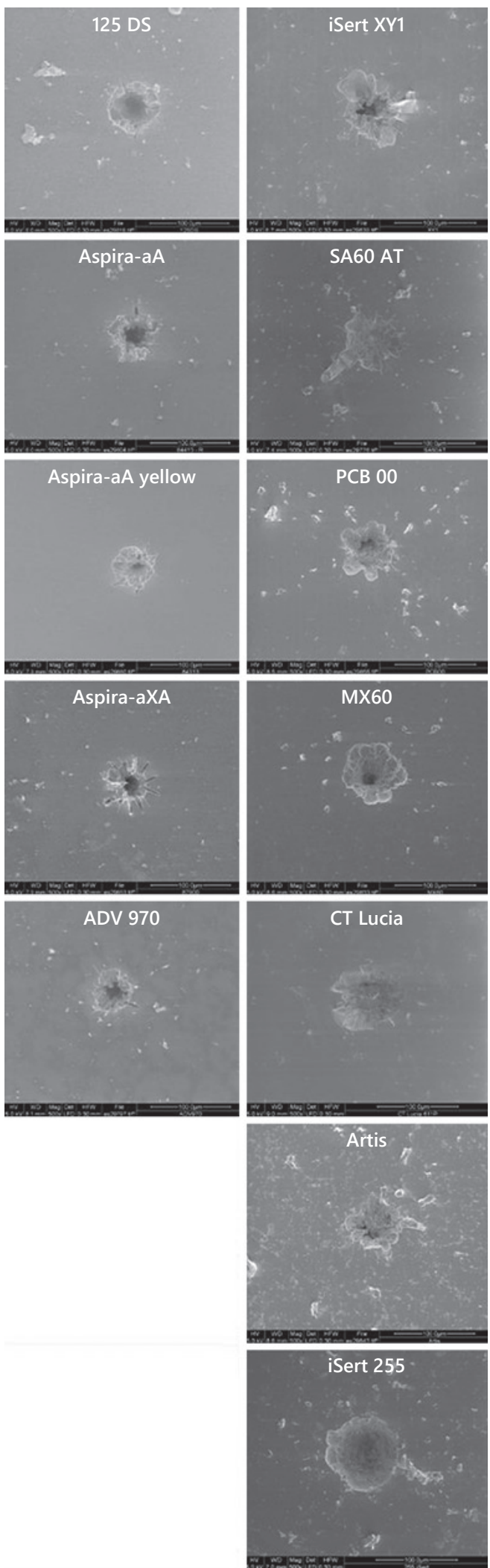

terms of changes in optical properties from before to after the treatment. Table 2 shows the results for the apertures of 2.0, 3.0, and $4.5 \mathrm{~mm}$ at all spatial frequencies. Wave front analysis (Fig. 11) showed besides the wellknown color map of the power of the lens unusual white spots. These white spots occur when an area of the sensor has not been illuminated. This happens when the beam deflection at a defined point of the lens is so large that the light beam no longer falls into the corresponding microlens. This happens in case of damage and material defects. A correlation between the position of the white spots and the indicated height differences was detected by the microscope. In some IOL samples, the power changes in the surrounding area of the defect - correlating to the measured Raman spectroscopy evaluation was detected.

The attempt to show the impact of the defects with a straylight analysis device or measure halo/glare in the IOL objectively, failed. The minimum measuring zone is too large for the tiny defect to be able to prove significant differences although one could suspect effects.

\section{Discussion}

In some long-term observations, hydrophobic IOLs supposedly outstand hydrophilic lenses in terms of economic results with lower PCO rates [15]. However, a comparison of hydrophilic and hydrophobic lenses in pediatric patients found the same rate of PCO development in both materials [16]. The authors found that IOL material was less important in PCO formation than their surgical technique including primary posterior capsulotomy and anterior vitrectomy. Other studies confirm that material is not the sole cause but edge design [5] and many other parameters [6] also play their role in PCO development. PCO remains the most common long-term postoperative complication of cataract surgery. Nd:YAG rates commonly reported before 1992 were between 20.3 and $33.4 \%$; while Nd:YAG rates for IOLs implanted 10 years later were below $17.1 \%$ [17]. In the past, numerous studies on various IOLs showed very different, unsteady results of Nd:YAG and PCO rates (5.0-20.0\%) 3-5 years after surgery [18].

Fig. 4. SEM images of the 5 hydrophilic IOLs (left column) and 7 hydrophobic IOLs (right column) included in this study showing damage after Nd:YAG laser treatment. IOLs, intraocular lenses; Nd:YAG, neodymium:yttrium aluminum garnet. 
Fig. 5. Boxplot showing the visible defect length $(\mu \mathrm{m})$ in the horizontal and vertical direction for both groups.

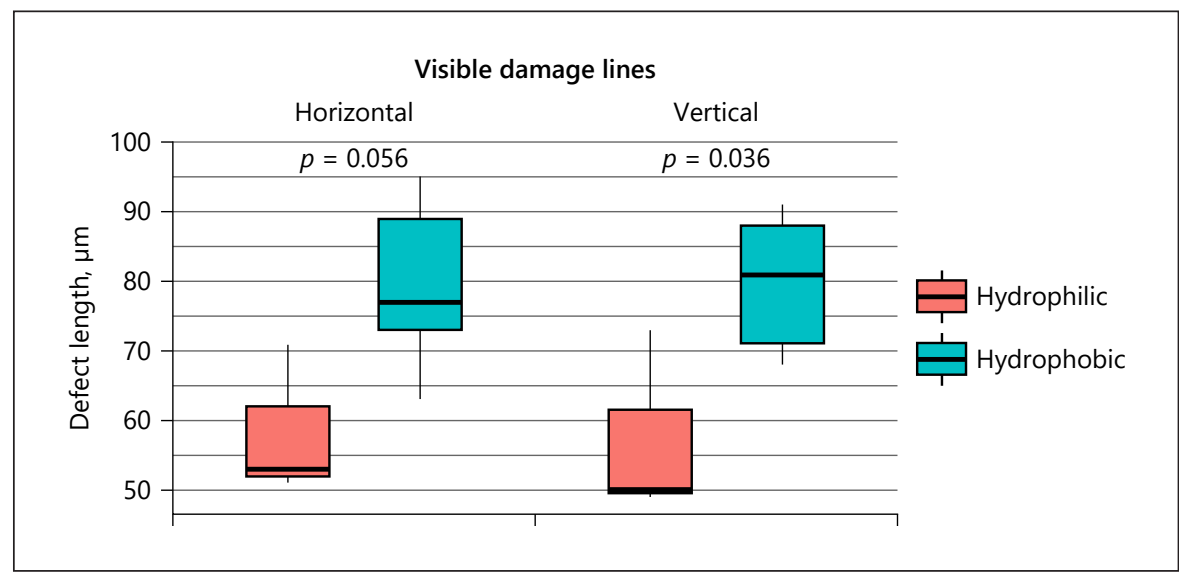

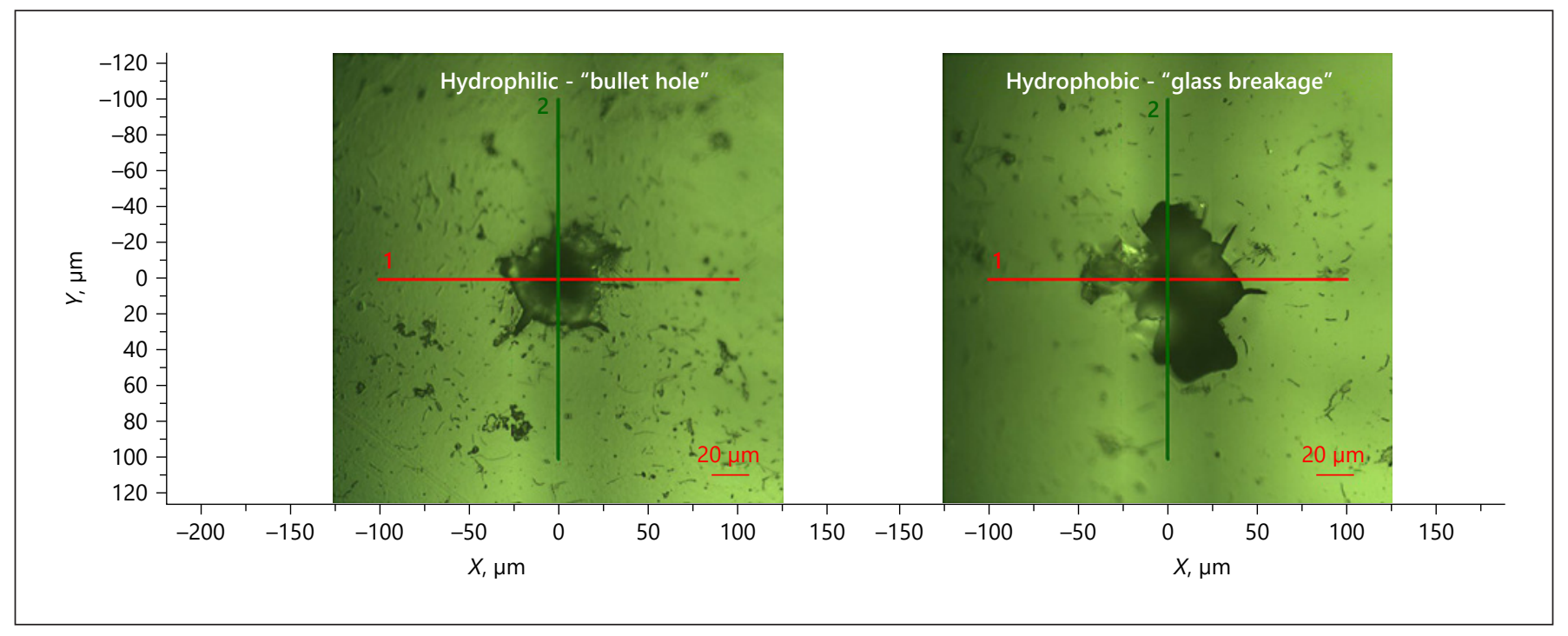

Fig. 6. Raman images showing the difference in damage size between hydrophilic (left) and hydrophobic (right) lens materials.

Nd:YAG laser treatment is an effective, quick, and relatively easy outpatient procedure, but it can produce complications [8] such as a transient rise in intraocular pressure [9], drop in VA, cystoid macular edema, retinal detachment, luxation/decentration of the IOL, or damage in the IOL material [10]. A Peyman or central Abraham contact lens is used to stabilize the eye, improving the laser beam optics, and facilitate accurate focusing. The minimal amount of energy necessary to obtain breakdown and rupture the capsule is desired. With most lasers, a typical capsule can be opened by using 1-2 mJ/ pulse.

Nd:YAG laser capsulotomy is used commonly to treat PCO after cataract surgery. Pitting of IOLs occurs in 15-
33\% of eyes during Nd:YAG laser posterior capsulotomy [19]. In the past, incorrect and inaccurate focusing of the laser beam was identified as the main factor of pitting. In several cases, time pressure could be determined as the main cause. Pitting is supposedly not visually significant although rarely the damage may cause sufficient glare, straylight, and image degradation so that the damaged IOL must be explanted [20].

Capsulotomy is achieved by focusing pulses of a few $\mathrm{mJ}$ in energy to clear the visual axis. The 2 primary techniques are the cruciate pattern and the circular pattern, each has its benefits and downsides. The cruciate pattern involves using the YAG laser to create a cross pattern, which then allows the resultant capsule flaps to retract out 


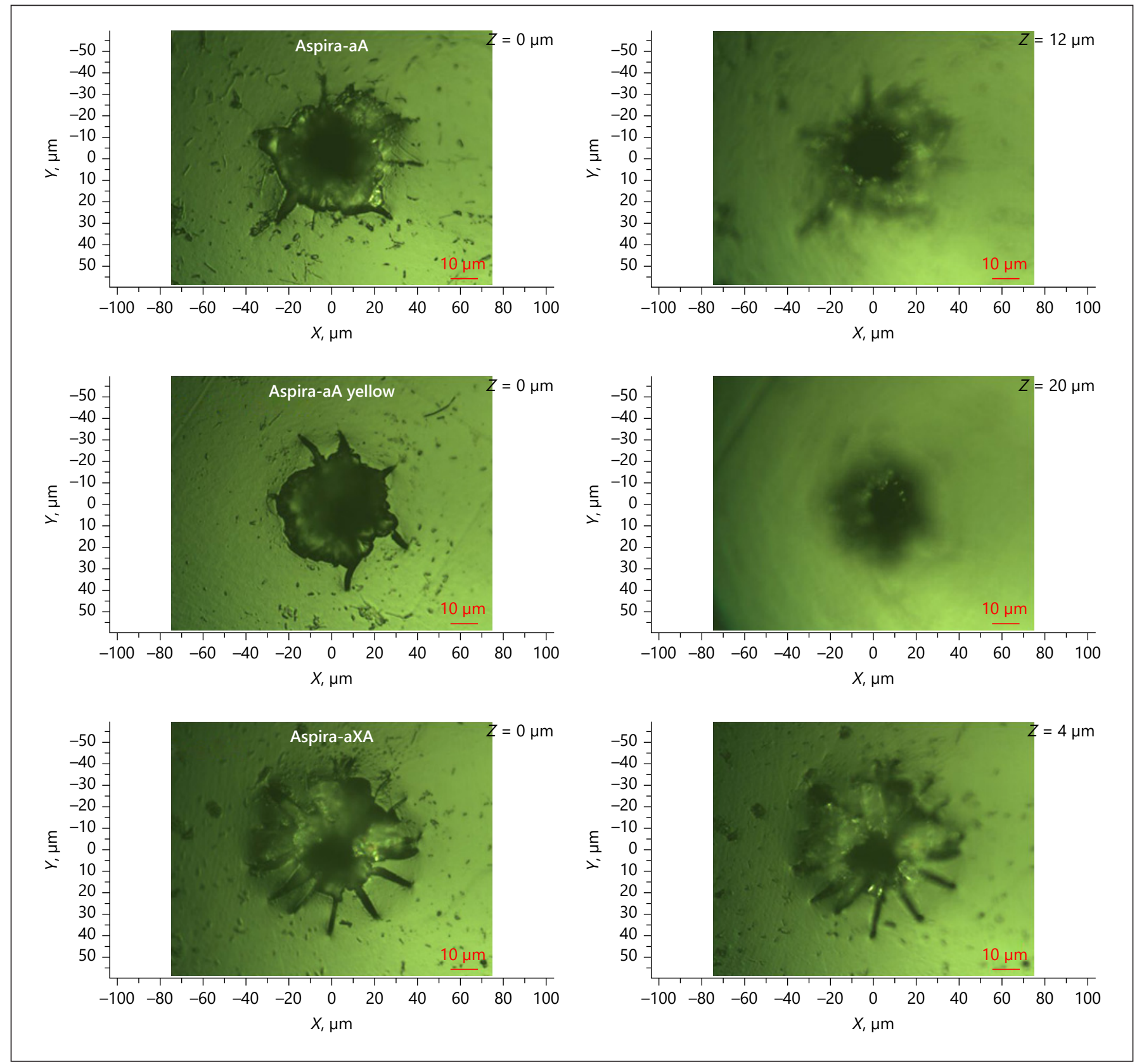

Fig. 7. Light microscopic images of the Raman measurements showing the size and depth of the defects created by Nd:YAG laser treatment in hydrophilic IOLs. IOLs, intraocular lenses; Nd:YAG, neodymium:yttrium aluminum garnet.

Fig. 8. Light microscopic images of the Raman measurements showing the size and depth of the defects created by Nd:YAG laser treatment in hydrophobic IOLs. IOLs, intraocular lenses; Nd:YAG, neodymium:yttrium aluminum garnet.

(For figure see next page.) 


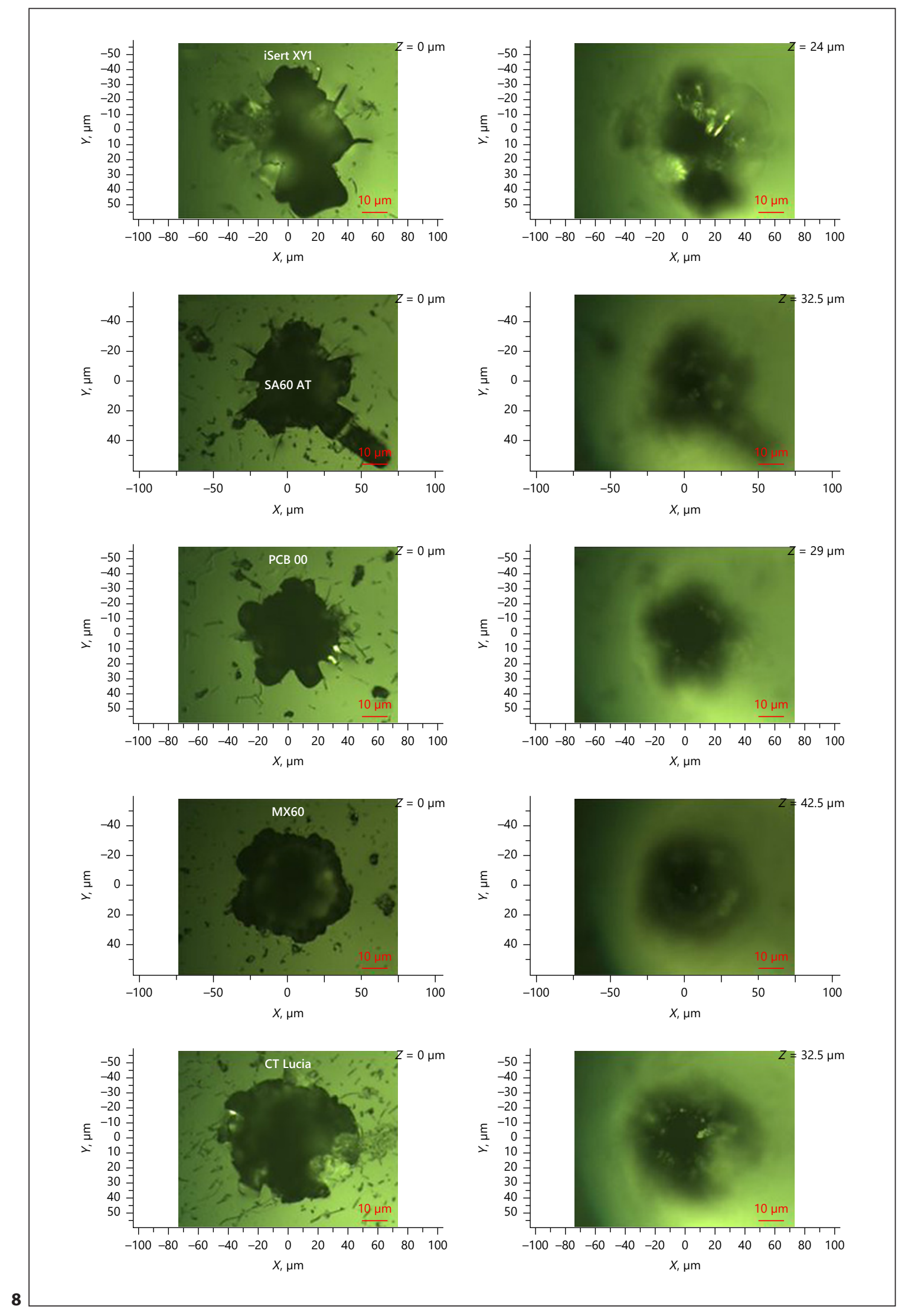


Fig. 9. Example of a Raman line scan showing the area of chemical changes after Nd:YAG laser treatment compared to a reference area in the outer periphery of the IOL. IOLs, intraocular lenses; Nd:YAG, neodymium:yttrium aluminum garnet.

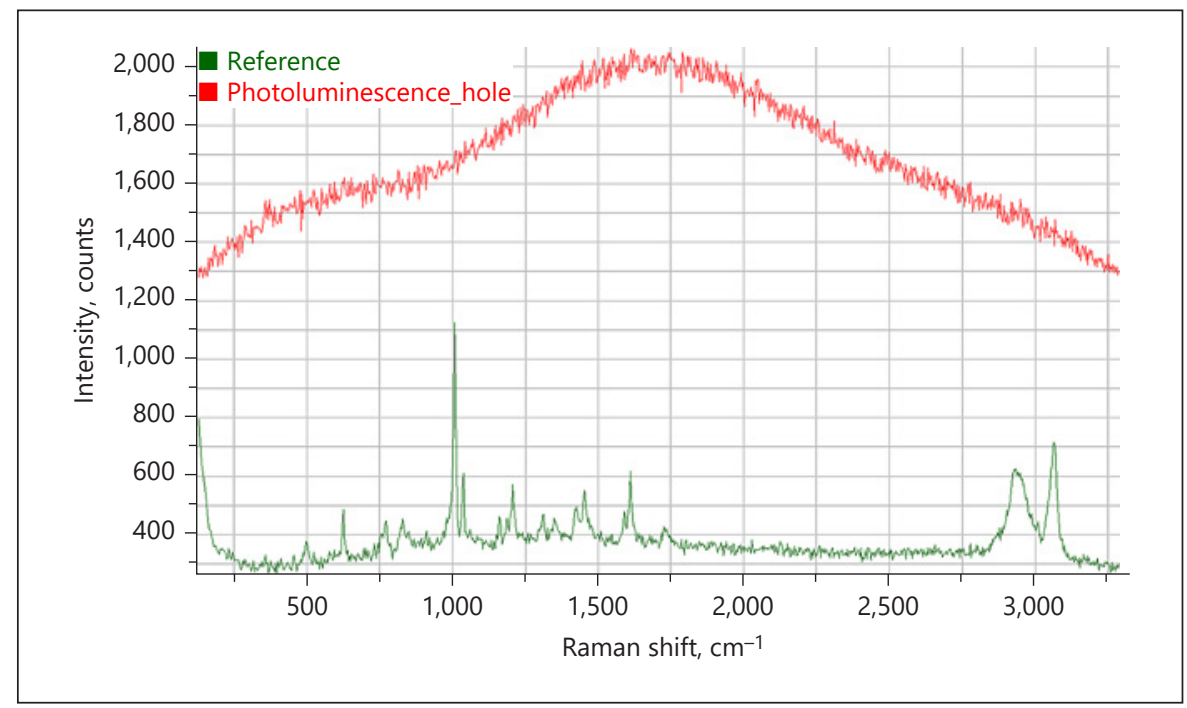

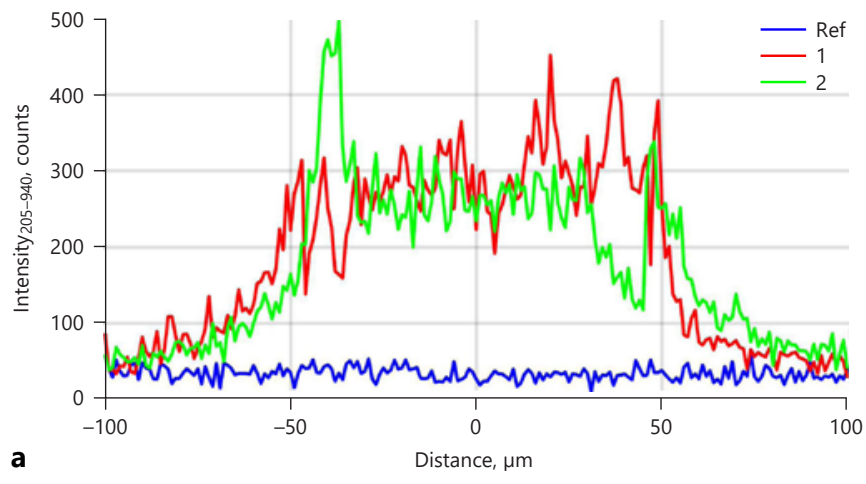

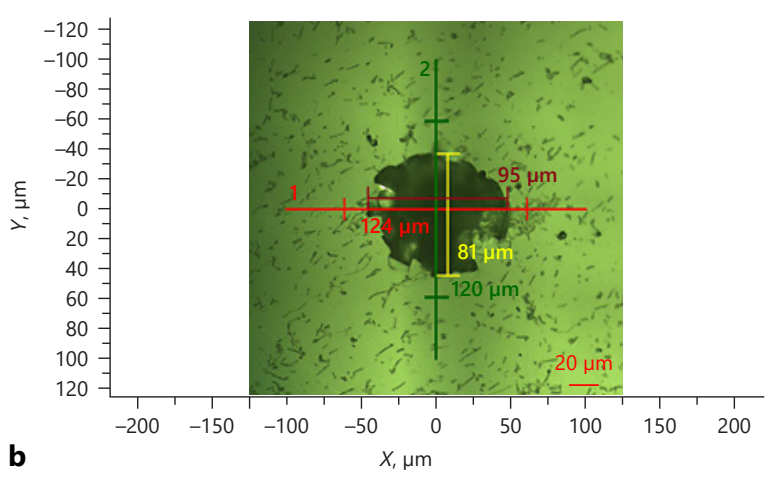

Fig. 10. Photoluminescence signal for the chemical changes (red = horizontal measurement, green = vertical measurement, and blue $=$ intact material) of a hydrophobic material (a) and Raman

of the visual axis. Laser spots are placed through the center of the IOL. Therefore, care must be taken to properly aim the laser to avoid pitting the optic in the central visual axis. The circular pattern creates a circular cutout, which then allows for a round posterior capsular opening. With this method, laser shots do not need to be placed in the central optical zone but in the periphery. Therefore, the chance of central pitting and negative effects on the optics is lower.

The capsulotomy procedure is considered a safe treatment although complications might occur [21]. However, there is little understanding on how the treatment in- spectroscopic image (b) with highlighted lengths of the chemical changes (bright red and green line) and the visible damage (dark red and yellow line). fluences IOL material. Bhargava et al. [12] found that required laser energy levels were influenced by the type of PCO but not by the IOL biomaterial and that complications were associated with higher total laser energy levels. Moreover, they found that different IOL materials had different damage thresholds, which were also associated to higher energy levels and incorrect focusing of the laser beam. Therefore, it is recommended to focus the beam posterior to the posterior capsule and keep the energy level as low as possible.

Some researchers also found that the frequency of IOL damage [20] depends on the IOL design. A design 
Table 2. The amount of changes from before to after the Nd:YAG procedure for the 2 groups measured with an aperture of $2.0 \mathrm{~mm}$

\begin{tabular}{|c|c|c|c|}
\hline Parameter & Hydrophilic & Hydrophobic & $p$ value \\
\hline $\begin{array}{l}\text { Aperture: } 2.0 \mathrm{~mm} \\
\text { Strehl ratio }\end{array}$ & $\begin{array}{l}-0.01 \pm 0.01 \\
0.00(-0.02 \text { to } 0.00)\end{array}$ & $\begin{array}{l}0.02 \pm 0.05 \\
0.00(-0.01 \text { to } 0.13)\end{array}$ & 0.15 \\
\hline MTF $25 \mathrm{lp} / \mathrm{mm}$ & $\begin{array}{l}0.00 \pm 0.00 \\
0.00(0.00 \text { to } 0.00)\end{array}$ & $\begin{array}{l}0.01 \pm 0.03 \\
0.00(-0.01 \text { to } 0.07)\end{array}$ & 0.76 \\
\hline MTF $50 \mathrm{lp} / \mathrm{mm}$ & $\begin{array}{l}0.00 \pm 0.00 \\
0.00(0.00 \text { to } 0.00)\end{array}$ & $\begin{array}{l}0.02 \pm 0.07 \\
0.00(-0.01 \text { to } 0.17)\end{array}$ & 0.76 \\
\hline MTF 100 lp/mm & $\begin{array}{l}0.00 \pm 0.01 \\
0.00(-0.01 \text { to } 0.01)\end{array}$ & $\begin{array}{l}0.01 \pm 0.04 \\
0.00(-0.01 \text { to } 0.11)\end{array}$ & 1.00 \\
\hline $\begin{array}{l}\text { Aperture: } 3.0 \mathrm{~mm} \\
\text { Strehl ratio }\end{array}$ & $\begin{array}{l}-0.01 \pm 0.02 \\
0.00(-0.03 \text { to } 0.01)\end{array}$ & $\begin{array}{l}0.01 \pm 0.05 \\
0.00(-0.06 \text { to } 0.11)\end{array}$ & 1.00 \\
\hline MTF $25 \mathrm{lp} / \mathrm{mm}$ & $\begin{array}{l}0.00 \pm 0.00 \\
0.00(0.00-0.00)\end{array}$ & $\begin{array}{l}0.01 \pm 0.01 \\
0.00(-0.01 \text { to } 0.03)\end{array}$ & 0.53 \\
\hline MTF $50 \mathrm{lp} / \mathrm{mm}$ & $\begin{array}{l}-0.01 \pm 0.01 \\
-0.01(-0.01 \text { to } 0.00)\end{array}$ & $\begin{array}{l}0.01 \pm 0.04 \\
0.00(-0.03 \text { to } 0.09)\end{array}$ & 0.27 \\
\hline MTF $100 \mathrm{lp} / \mathrm{mm}$ & $\begin{array}{l}-0.01 \pm 0.01 \\
-0.01(-0.02 \text { to } 0.01)\end{array}$ & $\begin{array}{l}0.01 \pm 0.06 \\
0.00(-0.06 \text { to } 0.11)\end{array}$ & 0.64 \\
\hline $\begin{array}{l}\text { Aperture: } 4.5 \mathrm{~mm} \\
\text { Strehl ratio }\end{array}$ & $\begin{array}{l}-0.01 \pm 0.06 \\
0.01(-0.10 \text { to } 0.04)\end{array}$ & $\begin{array}{l}0.01 \pm 0.05 \\
0.00(-0.06 \text { to } 0.11)\end{array}$ & 0.76 \\
\hline MTF $25 \mathrm{lp} / \mathrm{mm}$ & $\begin{array}{l}-0.01 \pm 0.02 \\
0.00(-0.03 \text { to } 0.02)\end{array}$ & $\begin{array}{l}0.00 \pm 0.02 \\
0.00(-0.03 \text { to } 0.03)\end{array}$ & 0.53 \\
\hline MTF $50 \mathrm{lp} / \mathrm{mm}$ & $\begin{array}{l}-0.01 \pm 0.04 \\
0.00(-0.09 \text { to } 0.03)\end{array}$ & $\begin{array}{l}0.01 \pm 0.03 \\
0.00(-0.04 \text { to } 0.04)\end{array}$ & 0.43 \\
\hline MTF 100 lp/mm & $\begin{array}{l}-0.01 \pm 0.06 \\
0.01(-0.10 \text { to } 0.04)\end{array}$ & $\begin{array}{l}0.00 \pm 0.02 \\
0.01(-0.04 \text { to } 0.02)\end{array}$ & 1.00 \\
\hline
\end{tabular}

Nd:YAG, neodymium:yttrium aluminum garnet; MTF, modulation transfer function.

separating the posterior capsule from the IOL (ridge) is less prone to damage than lenses with a close apposition between the IOL posterior surface and the posterior capsule. Current attempts to reduce or prevent PCO by having posterior capsule adhesion to the IOL might complicate laser treatment and increase rates of damage.

Differences between the materials in terms of wavefront quality were observed by Rozema et al. [11]. They measured wavefront aberrations in hydrophilic and hydrophobic IOLs before and 2 weeks after the Nd:YAG procedure. Before or after the procedure no significant differences were found between the 2 groups. Within the groups, there were nonsignificant changes before and after the treatment in the hydrophilic group but significant reduction of the RMS and peak to valley values in the hydrophobic group. These observations were the same for the whole cohort, indicating a flattening of the wavefront after capsulotomy [22]. Even with the suggested lower laser energy levels, defects still occur, which is why we investigated the differences of the defects between hydrophilic and hydrophobic IOL materials. Our results show that the treatment has greater impact on hydrophobic lenses as the defects are larger in terms of depth and width/diameter and more frayed than in hydrophilic lenses. 


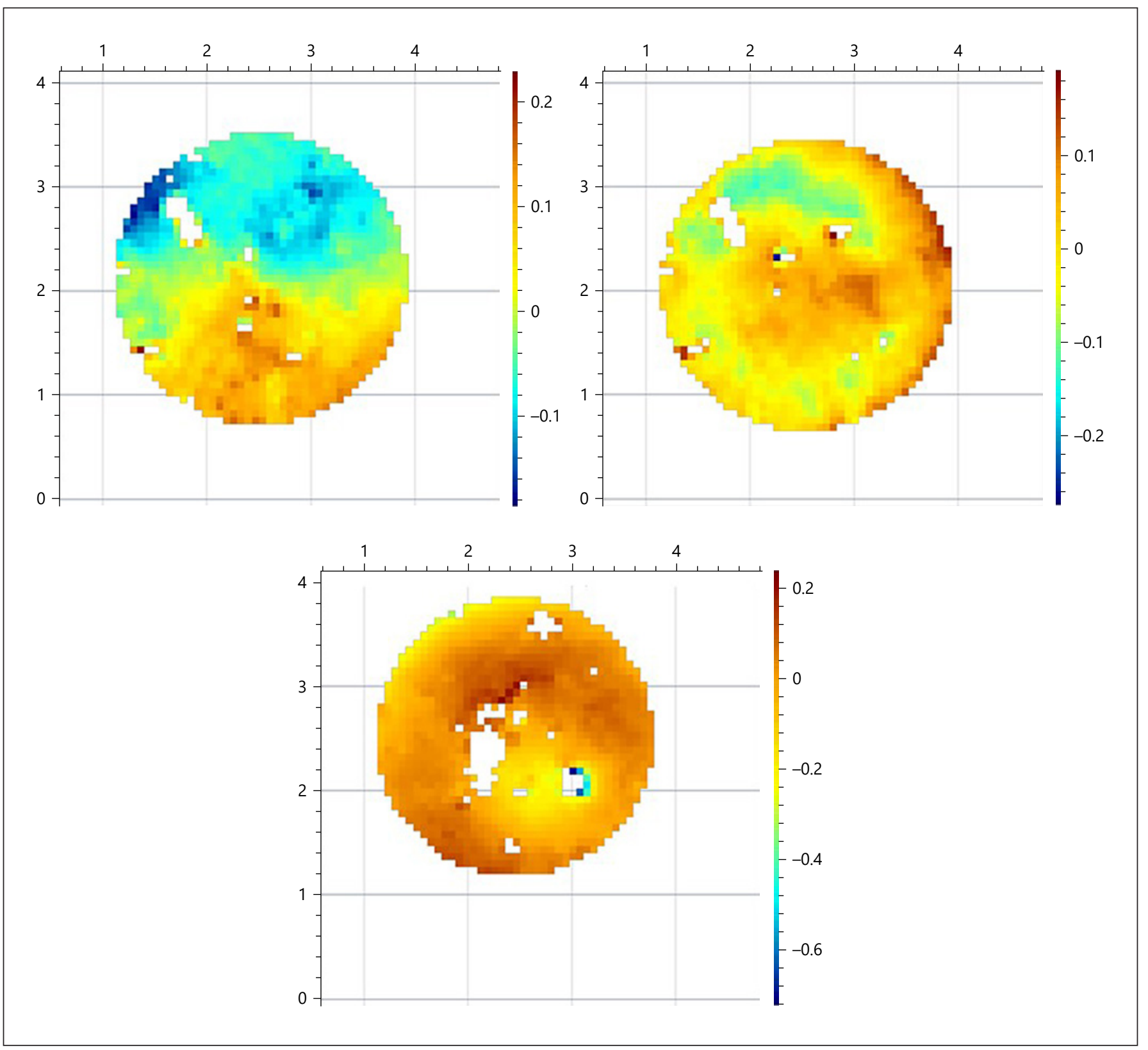

Fig. 11. Examples of IOL wavefront analysis, showing white spots. IOL, intraocular lens.

We failed to see differences in the optical properties after the laser procedure between the 2 material types, though research indicates that these differences exist to some degree [22]. Our measurements followed a standardized protocol with the IOLs having the same diopter and using the same laser energy level for all lenses within the same setting. The sample size in this study is a limitation and we intend to repeat these measurements in a greater cohort with monofocal, multifocal, and toric lenses in future trials.

Our light microscopic images, however, show differences between the 2 materials in terms of size of the defects. Confirmed by the spectroscopic measurements, it seems that hydrophobic lenses are more prone to greater defects in size and depth. Moreover, the defect shape in hydrophilic lenses is more circular than in hydrophobic 

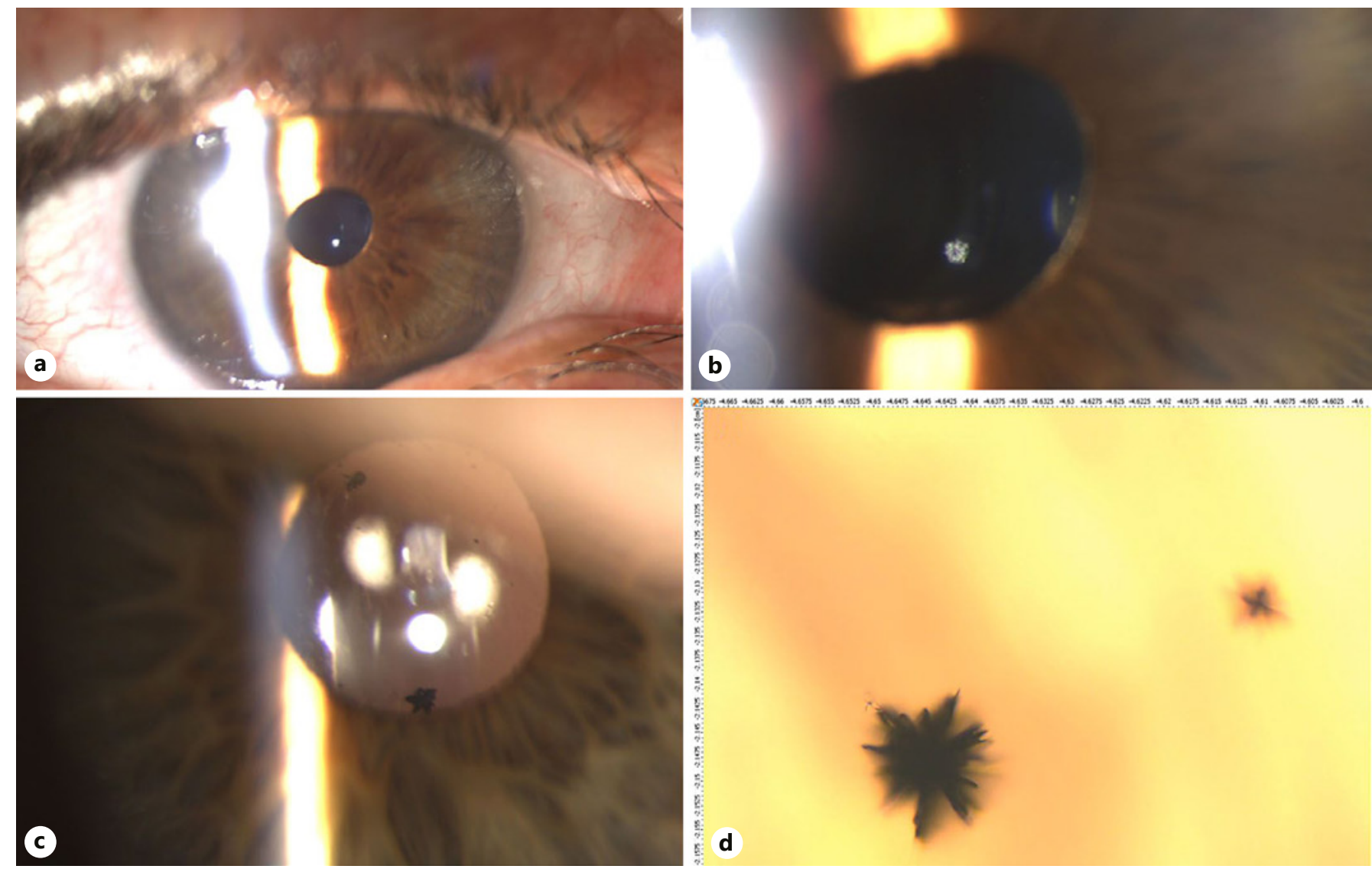

Fig. 12. Slit lamp images of an IOL with YAG defect (a-c) within the pupil area of a patient and reflective light microscopic image of the defects (d). IOL, intraocular lens.

lenses. Defects can be seen even within standard slit lamp examination (Fig. 12a-c). A patient reported of disturbing glare especially from headlights in traffic and higher photosensitivity after a YAG procedure. The YAG shot was visible in the non-dilated pupil $(1.9 \mathrm{~mm})$ during slit lamp examination with standard magnification settings. Reflective light microscopy (Fig. 12d) makes it obvious that those dark spots might be visually disturbing to the patient when positioned within the pupil area and the central part of the optic. Moreover, the dark color of the laser defects and patient-reported discomfort might be misinterpreted as pigment deposits leading to another YAG procedure by another ophthalmologist [23].

Despite nonsignificant differences found in the Raman spectroscopy for the visible damage lengths, those values were close to the $5.0 \%$ significance level and therefore should be under evaluation in another larger cohort study. The values do seem to have clinically significant differences, which might imply that hydrophilic lenses gain smaller YAG damages than hydrophobics. Studies on a larger sample size may be required to further substantiate this observation. However, these measurements confirm the subjectively observed differences within imaging of the defects. We found evidence that the material changes chemically due to the procedure. Those changes seem to be greater than visually observable (Fig. 10). If we take this image of a hydrophobic lens as an example, we can see a visible damage of $81 \mu \mathrm{m}$ (vertical) and $95 \mu \mathrm{m}$ (horizontal) but the chemical changes increase to $120 \mu \mathrm{m}$ (vertical) and $124 \mu \mathrm{m}$ (horizontal) which is an enlargement of 48 and $31 \%$, respectively. This means that the area of the defect in the IOL is not 7,600 $\mu \mathrm{m}^{2}$ (visible area) but $14,800 \mu \mathrm{m}^{2}$ (actual area), twice as large.

The results are most likely explained by the different water content of hydrophilic and hydrophobic IOLs. Materials with lower water content might be more prone to $\mathrm{Nd}$ :YAG damage due to their rigidity [24]. A higher water content goes along with more flexibility and less risk for 
glistening formation, which might explain the current trend to develop hydrophobic materials with a slightly higher water content $[25,26]$. Biological samples are usually mostly made up of water and have a low absorption coefficient at the wavelength of 1,064 nm (Nd:YAG) [27]. A low absorption coefficient minimizes damage to the biological material. More studies have to be performed analyzing the changes in the chemical structure and/or potentially toxic agents or self-focusing effects of the YAG laser at transitions between materials.

\section{Conclusion}

The type, style, configuration, and extent of lens damage depends on the material used to manufacture IOLs. In the course of the project, it could be shown that the defects generated by the YAG laser have differences in morphology depending on whether a hydrophilic (high water content) and hydrophobic (low water content) IOL is present. The surface structure damage in hydrophobic IOLs is more like a brittle fracture with sharp edges, whereas the defects in hydrophilic IOLs are more like drilled holes. The Raman line scans have shown that the area in which the IOLs have been chemically damaged is much larger than that in which a damage is visually recognizable. It follows that the functionality of the IOL, for example, due to a changed refractive index, can be significantly more limited than one would conclude from a simple inspection. It could be shown that the water content plays a prominent role. Our results show that hydrophilic lenses tend to be less negatively affected by Nd:YAG laser than hydrophobic lenses in terms of size and shape of the defects. When performing Nd:YAG, it should be considered that damage might appear and influence the optical properties of the lens especially when performed centrally. It should be borne in mind that the area of chemical changes seems to be greater than the area of visible defects. The size and position of the defect, the material of the lens as well as the water content play a decisive role. It can be assumed that this could have an even greater, negative effect in premium IOLs. Inadequate laser treatment of PCO with associated IOL damage might have a greater impact on overall IOL performance as we thought. Even if the clinical symptoms for patients usually remain low, an additional impairment and deterioration of the optical quality of the IOL may be associated with the location of the defect. This fact should be proven and verified clinically with new examination devices, such as the C-Quant
(Oculus, Germany). More studies are carried out and realized by the authors right now.

Therefore, the YAG capsulotomy should not be considered trivial but should be carried out with precision and without time pressure, just like the surgery itself. More studies (in vivo and in vitro) with large number of cases of different IOL models including monofocal, toric, and multifocal (premium) lenses are needed. In times of refractive procedures and premium lenses with quite rightly high patients' expectations, the avoidance of YAG shots/pitting is just as important as the prevention of glistenings, calcification, or negative dysphotopsia. The results of this study should draw attention to the topic and be the start for larger follow-up studies.

\section{Acknowledgment}

In particular, I would like to thank my family, as so much time and money has been invested to finalize this paper. The study was financed by private funds only, in order to remain completely independent and achieve objective results.

\section{Statement of Ethics}

This study complies with the guidelines for human studies and the research was conducted ethically in accordance with the World Medical Association Declaration of Helsinki. As it is an experimental study (in vitro), no ethical approval was necessary.

\section{Conflict of Interest Statement}

A.F.B. and E.-M.B. have no financial or proprietary interest in any material or method mentioned.

\section{Funding Sources}

This study was conducted with private funding (authors: A.F.B and E.-M.B.) and without any additional funding by companies or sponsors. The authors received no financial support for the research, authorship, and/or publication of this article.

\section{Author Contributions}

Both authors (A.F.B. and E.-M.B.) provided substantial contributions to data acquisition or data analysis and interpretation. All authors drafted the article and critically revised it. All authors approved the final version to be published. 


\section{References}

1 Nagy ZZ, Popper-Sachetti A, Kiss HJ. Comparison of visual and refractive outcomes between hydrophilic and hydrophobic trifocal intraocular lenses sharing the same optical design. J Cataract Refract Surg. 2019;45(5): 553-61.

2 Chang A, Kugelberg M. Glistenings 9 years after phacoemulsification in hydrophobic and hydrophilic acrylic intraocular lenses. J Cataract Refract Surg. 2015;41(6):1199-204.

3 Zhao Y, Yang K, Li J, Huang Y, Zhu S. Comparison of hydrophobic and hydrophilic intraocular lens in preventing posterior capsule opacification after cataract surgery: an updated meta-analysis. Medicine. 2017;96(44): e8301.

4 Abela-Formanek C, Amon M, Schild G, Schauersberger J, Heinze G, Kruger A. Uveal and capsular biocompatibility of hydrophilic acrylic, hydrophobic acrylic, and silicone intraocular lenses. J Cataract Refract Surg. 2002; 28(1):50-61.

5 Buehl W, Findl O. Effect of intraocular lens design on posterior capsule opacification. J Cataract Refract Surg. 2008;34(11):1976-85.

6 Meacock WR, Spalton DJ, Boyce JF, Jose RM. Effect of optic size on posterior capsule opacification: $5.5 \mathrm{~mm}$ versus $6.0 \mathrm{~mm}$ AcrySof intraocular lenses. J Cataract Refract Surg. 2001; 27(8):1194-8.

7 Karahan E, Er D, Kaynak S. An overview of Nd:YAG laser capsulotomy. Med Hypothesis Discov Innov Ophthalmol. 2014;3(2):45-50.

8 Siegl H, Pinz A, Buhl W, Georgopoulos M, Findl O, Menapace R. Assessment of posterior capsule opacification after cataract surgery. Bergen, Proceedings of the Scandinavian Conference on Image Analysis 2001. p. 5461.

9 Shetty NK, Sridhar S. Study of variation in intraocular pressure spike (IOP) following NdYAG laser capsulotomy. J Clin Diagn Res. 2016;10(12):NC09.
10 Uzel MM, Ozates S, Koc M, Taslipinar Uzel AG, Yilmazbaș P. Decentration and tilt of intraocular lens after posterior capsulotomy. Semin Ophthalmol. 2018;33(6):766-71.

11 Rozema JJ, Koppen C, de Groot V, Tassignon MJ. Influence of neodymium:YAG laser capsulotomy on ocular wavefront aberrations in pseudophakic eyes with hydrophilic and hydrophobic intraocular lenses. J Cataract Refract Surg. 2009;35(11):1906-10.

12 Bhargava R, Kumar P, Phogat H, Chaudhary KP. Neodymium-yttrium aluminium garnet laser capsulotomy energy levels for posterior capsule opacification. J Ophthalmic Vis Res. 2015;10(1):37-42.

13 R Core Team. R: A language and environment for statistical computing. Vienna, Austria: R Foundation for Statistical Computing; 2019. Available from: https://www.R-project.org/.

14 Wickham H. ggplot2: elegant graphics for data analysis. New York: Springer; 2009.

15 Kossack N, Schindler C, Weinhold I, Hickstein L, Lehne M, Walker J, et al. German claims data analysis to assess impact of different intraocular lenses on posterior capsule opacification and related healthcare costs. Z Gesundh Wiss. 2018;26(1):81-90.

16 Sen P, Kshetrapal M, Shah C, Mohan A, Jain E, Sen A. Posterior capsule opacification rate after phacoemulsification in pediatric cataract: hydrophilic versus hydrophobic intraocular lenses. J Cataract Refract Surg. 2019; 45(10):1380-5.

17 Apple DJ, Peng Q, Visessook N, Werner L, Pandey SK, Escobar-Gomez M, et al. Eradication of posterior capsule opacification: documentation of a marked decrease in Nd:YAG laser posterior capsulotomy rates noted in an analysis of 5,416 pseudophakic human eyes obtained postmortem. Ophthalmology. 2001; 108(3):505-18.

18 Ursell PG, Dhariwal M, O’Boyle D, Khan J, Venerus A. 5 year incidence of YAG capsulotomy and PCO after cataract surgery with single-piece monofocal intraocular lenses: a real-world evidence study of 20,763 eyes. Eye. 2020 May;34(5):960-8.
19 Steinert RF. Neodymium:yttrium-aluminium-garnet laser posterior capsulotomy. In: Cataract surgery: expert consult - online and print. 2009

20 Steinert RF. Nd:YAG Laser Posterior Capsulotomy. American Academy of Ophthalmology, 2013. Available from: https://www.aao. org/munnerlyn-laser-surgery-center/ndyaglaser-posterior-capsulotomy-3 Accessed 2020 July 5.

21 Khreish M, Hanna R, Berkovitz L, Tiosano B. Corneal perforation after Nd:YAG capsulotomy: a case report and literature review. Case Rep Ophthalmol. 2019 Jan-Apr;10(1):111-5.

22 Trinavarat A, Atchaneeyasakul L, Udompunturak S. Neodymium:YAG laser damage threshold of foldable intraocular lenses. J Cataract Refract Surg. 2001;27(5):775-80.

23 Newland T, Auffarth G, Wesendahl T, Blotnik C. Apple D Oberflächenschäden von Silikon-IOL-Optiken durch Nd:YAG-Laser: Befunde bei explantierten Intraokularlinsen. Kongreß der Deutschsprachigen Gesellschaft für Intraokularlinsen Implantation. Springer; 1993. Vol. 7, p. 391-6.

24 Dick B, Schwenn O, Pfeiffer N. [Extent of damage to different intraocular lenses by neodymium:YAG laser treatment: an experimental study]. Klin Monbl Augenheilkd. 1997; 211(4):263-71.

25 Pagnoulle C, Bozukova D, Gobin L, Bertrand V, Gillet-De Pauw MC. Assessment of newgeneration glistening-free hydrophobic acrylic intraocular lens material. J Cataract Refract Surg. 2012;38(7):1271-7.

26 Werner L, Thatthamla I, Ong M, Schatz H, Garcia-Gonzalez M, Gros-Otero J, et al. Evaluation of clarity characteristics in a new hydrophobic acrylic IOL in comparison to commercially available IOLs. J Cataract Refract Surg. 2019;45(10):1490-7.

27 Walsh P. Lasers and their applications. EDTECH; 2018. 